\title{
Numerical Investigation of Wind Load Characteristics of Crescent-shape Iced OPGW
}

\author{
Wang $\mathrm{Fei}^{1}$, Dang Huixue ${ }^{2}$, Zhang Hongjie ${ }^{1}$, Yang Fengli ${ }^{1}$ \\ ${ }^{1}$ China Electric Power Research Institute, 100055, Beijing, China \\ ${ }^{2}$ School of Civil Engineering, Chang'an University, 710061, Xi'an, Shan Xi, China
}

Keywords: Crescent-shape; Iced OPGW; Shape Coefficient; Reynolds Number; Wind Angle; Numerical Investigation.

\begin{abstract}
Accounting for wind load characteristic of iced OPGW, flow field around OPGW optical fibre, with ice thickness of $5 \mathrm{~mm}$ and $20 \mathrm{~mm}$, respectively, are simulated by solving Naviver-Stokes equations enclosed by transition SST turbulence model, under different wind speed conditions. The results indicate that, shape coefficients of iced OPGW with ice thickness $5 \mathrm{~mm}$ or $20 \mathrm{~mm}$ are basically consistent with each other at wind speeds of both $5 \mathrm{~m} / \mathrm{s}$ and $15 \mathrm{~m} / \mathrm{s}$. It means that shape coefficients are not sensitive to Reynolds number under these two icing thickness conditions; increasing of icing thickness has obvious influence on shape coefficient under same wind speeds: in case wind angle is less than $50^{\circ}$ or greater than $120^{\circ}$, increase of icing thickness will decrease the shape coefficients of iced OPGW; in case wind angle lies within wind angle section of $50^{\circ} \sim 120^{\circ}$, windward area will increase following the increase of icing thickness, hence shape coefficients of OPGW will increase obviously, following increasing of icing thickness.
\end{abstract}

\section{Introduction}

The power transmission system in China is frequently suffering ice accident. Because cold air from north area and warm wet air from south converges at cold winter and beginning of spring every year, the freezing rain is liable to cause icing of the transmission conductors. Icing of the power transmission line will cause de-icing jump, galloping, line breakdown and tower collapse ${ }^{[1-5]}$, etc. Investigation on shape coefficient is developed on icing of the conductive grounding wire, and it is compared to value specified in the specification. It is not only used to analyze influence of icing on wind load of the conductive grounding wire and strength calibration of the power transmission tower but also used as input parameters and study galloping characteristic of the conductive grounding wire. Therefore it is a problem which must be managed, by using either wind tunnel tests or numerical simulation investigations.

For shape coefficient of the icing conductive grounding wire, Xiao Zhizheng ${ }^{[6]}$ etc take advantage of wind tunnel tests to compare and study aerodynamic force characteristic before and after the eight split conductor applied in the ultra-high voltage power transmission line, which systematically forwards three component coefficient and discusses disturbance of the upstream conductor on flow field and influence of wake effect on aerodynamic force characteristic of the conductor; Li Xinmin etc ${ }^{[7]}$ employed of NS equation enclosed by SA turbulence model to simulate and study three component coefficient of the typical crescent-shape, aerofoil, section shape and D shape icing conductor, and they pointed out aerodynamic force parameters of the icing conductor are only related to specification, icing thickness, icing type and attack angle etc of the conductor, and it is affected less by wind speed; Peng Jianing ${ }^{[8]}$ etc establishes two dimension CFD model of flow field around the icing conductor, and verifies accuracy and reliability of CFD numerical simulation method through comparison between numerical results of the iced bundle conductors in Hubei Zhongshankou and wind tunnel test data. Wang $\operatorname{Xin}^{[9]}$ et al. carried out wind tunnel test of aerodynamic force coefficient on the ultra (super) high voltage large section thick icing conductor in crescent shape and D shape two typical sections and the influence of turbulence on aerodynamic force coefficient taking advantage of even flow and even turbulence were studied and presented wind attack angle scopes where galloping may occur on the icing conductors in two sections 
according to Den Hartog theory; Zhang Hongyan ${ }^{[10]}$ et al. measured aerodynamic characteristic of the icing conductor at crescent shape and section shape under different wind speed taking advantage of the wind tunnel test, and obtained change rules of its resistant force, rise force coefficient and torque coefficient following attack angle of wind, result shows aerodynamic characteristic coefficient within tested wind speed scope is affected less by wind speed; $\mathrm{Lv} \mathrm{Yi}^{[11]}$ etc simulated aerodynamic characteristic of two typical icing triple bundled-conductors in crescent shape and section shape through solving NS equations, and pointed out shielding effect of the upstream conductor on the downstream conductor and galloping degree of sectional icing are more obvious compared to the crescent shape; Cai Mingqi ${ }^{[12]}$ et al. simulated aerodynamic characteristic of the icing four split conductor in 2D crescent based on NS equations enclosed by SA turbulence, and obtained three component coefficient results consistent to the wind tunnel test. Previous studies of three component coefficient are basically developing based on wind tunnel test or 2D numerical simulations, but for the icing conductor etc bluff bodies, its separated flow within sub-critical Reynolds number scope has obvious three dimension effect. In order to accurately simulate its three dimensional flow fields, it is necessary to apply the 3D numerical model, with transient simulations conducted. This paper establishes a 3D numerical model to developed for shape coefficients of the iced OPGW.

\section{Governing equations and grid}

The governing equations applied in this paper is Reynolds average integral three dimensional $\mathrm{N}-\mathrm{S}$ equation, it can be written as follows in Cartesian coordinate systems:

$$
\frac{\partial}{\partial t} \iiint_{\Omega} \vec{Q} d V+\iint_{\partial \Omega} \vec{F}(\vec{Q}) \cdot \vec{n} d S=\iint_{\partial \Omega} \vec{G}(\vec{Q}) \cdot \vec{n} d S
$$

Considering the OPGW optical cable has typical bluff body cross section, its low speed streaming flow is related to complicate boundary transition, separation, re-attachment and periodic fall etc. Therefore the transition SST(shear stress transport) turbulence model is applied to simulate turbulence effect in this project. This turbulent model not only simulates flow separation and reattachment well under turbulent effect but also grasp transition flow of turbulence. This turbulent model consists of 4 governing equations. In which, transport equations of turbulent kinetic energy (turbulent kinetic energy) $^{k}$ and specific dissipation rate(specific dissipation rate) ${ }^{\omega}$ are:

$$
\begin{aligned}
& \frac{\partial(\rho k)}{\partial t}+\frac{\partial}{x_{i}}\left(\rho k u_{i}\right)=\frac{\partial}{\partial x_{j}}\left(\Gamma_{k} \frac{\partial k}{\partial x_{j}}\right)+\tilde{G}_{k}-Y_{k} \\
& \frac{\partial(\rho \omega)}{\partial t}+\frac{\partial}{x_{i}}\left(\rho \omega u_{i}\right)=\frac{\partial}{\partial x_{j}}\left(\Gamma_{\omega} \frac{\partial \omega}{\partial x_{j}}\right)+G_{\omega}-Y_{\omega}+D_{\omega}
\end{aligned}
$$

Equation of intermittency factor $\gamma$ is:

$$
\frac{\partial(\rho \gamma)}{\partial t}+\frac{\partial}{x_{j}}\left(\rho u_{j} \gamma\right)=P_{\gamma 1}-E_{\gamma 1}+P_{\gamma 2}-E_{\gamma 2}+\frac{\partial}{\partial x_{j}}\left(\left(\mu+\mu_{t}\right) \frac{\partial \gamma}{\partial x_{j}}\right)
$$

Initial rule of transition is:

$$
\gamma_{\text {sep }}=\min \left(2 \max \left[\left(\frac{\mathrm{Re}_{v}}{3.235 \mathrm{Re}_{\theta c}}-1,0\right) F_{\text {reattach }}, 2\right]\right) F_{\theta t}
$$

The transition control equation interacts with turbulent kinetic energy each other through the following way:

$$
\frac{\partial(\rho k)}{\partial t}+\frac{\partial}{x_{j}}\left(\rho k u_{j}\right)=\tilde{P}_{k}-\tilde{D}_{k}+\frac{\partial}{\partial x_{j}}\left(\left(\mu+\sigma_{k} \mu_{t}\right) \frac{\partial k}{\partial x_{j}}\right)
$$


Equation(3) Equation (5) are the four governing equations of Transition SST turbulence model. This equation group is dispersed by the discretization method proposed by Barth, T.J. ${ }^{[13]}$.

Diameter of the given optical cable is $11.4 \mathrm{~mm}$. For the crescent shape icing conditions in different thickness, the generated grids are shown as Fig.1 and Fig.2:
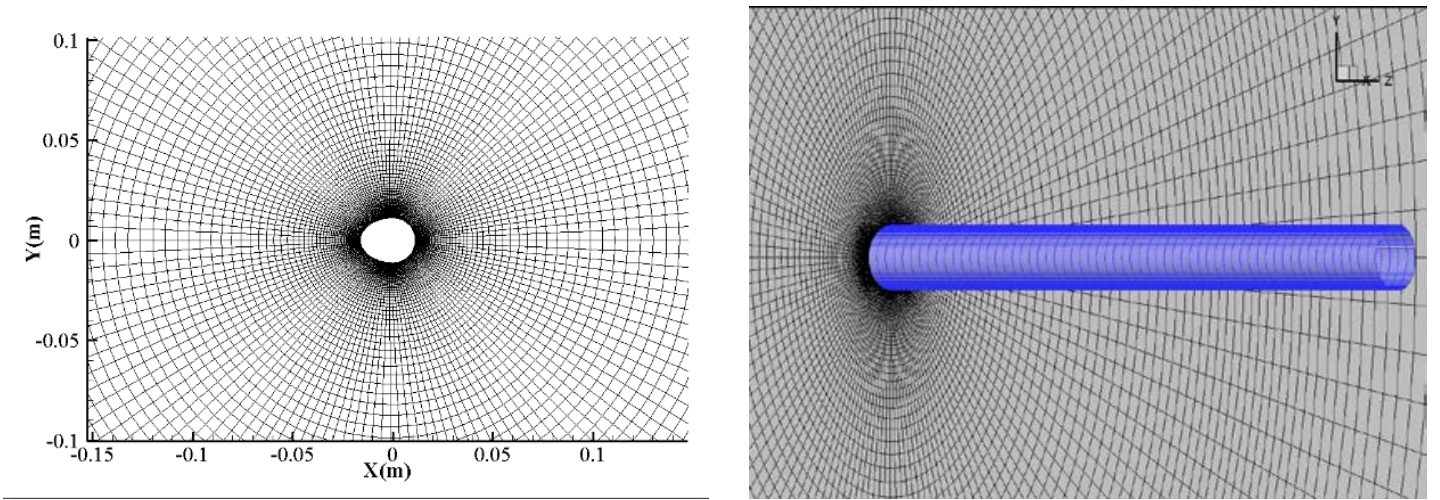

Fig.1 Symmetrical plane and spread grid of $0^{\circ}$ wind angle of $5 \mathrm{~mm}$ icing
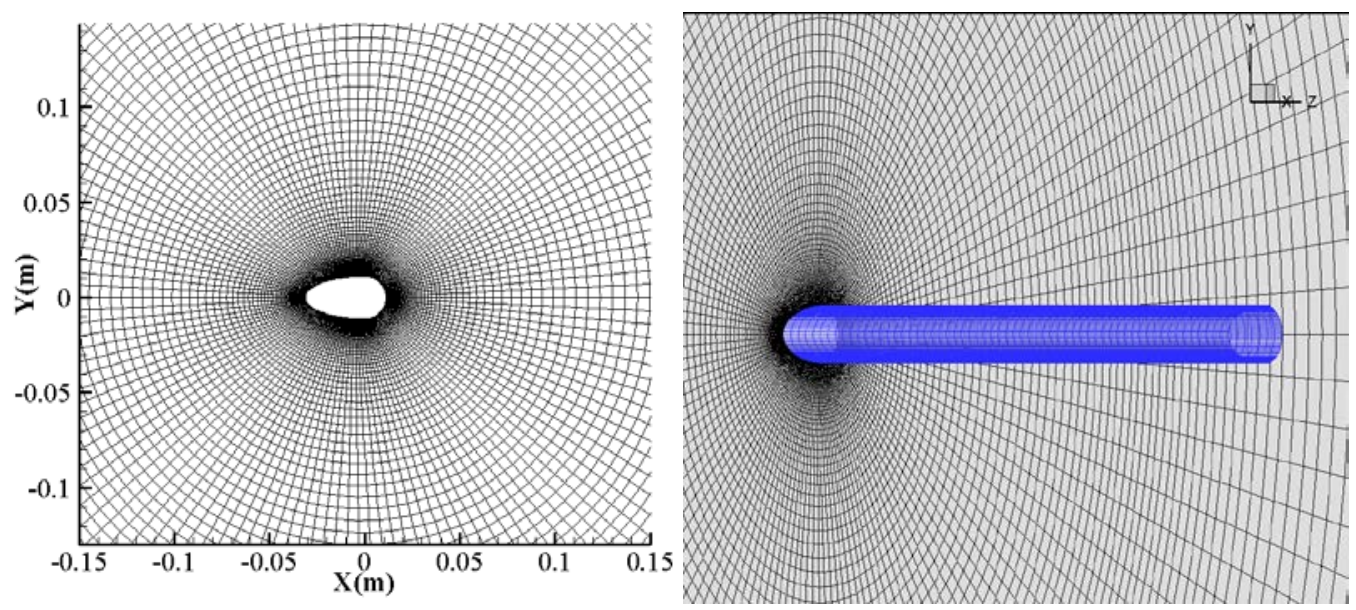

Fig.2 Symmetrical plane and spread grid of $0^{\circ}$ wind angle of $20 \mathrm{~mm}$ icing

In which, thickness of first layer of the grid is $5 \times 10^{-5} \mathrm{~m}$, corresponding $\mathrm{y}^{+}$is about 1.0 , which meets calculation requirement of turbulence model.

\section{Result of $5 \mathrm{~mm}$ icing}

Results at different wind angle under $5 \mathrm{~m} / \mathrm{s}$ and $15 \mathrm{~m} / \mathrm{s}$ wind speed conditions are shown as Fig. 3 and Fig.4 respectively. Seen from the figure, there is obvious three dimension effect on surface pressure distribution at leeward side.

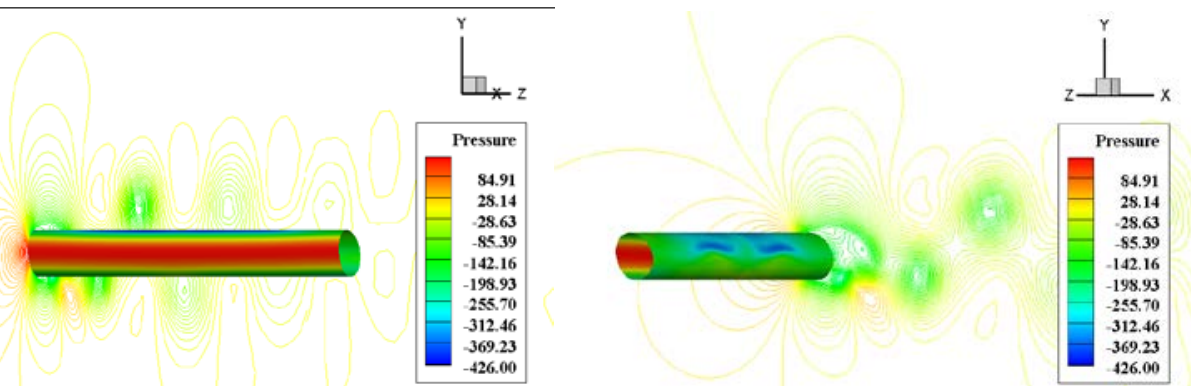

Fig.3 Surface pressure distribution of symmetrical plane and icing optical fibre at $60^{\circ}$ wind angle at wind speed of $15 \mathrm{~m} / \mathrm{s}$ 


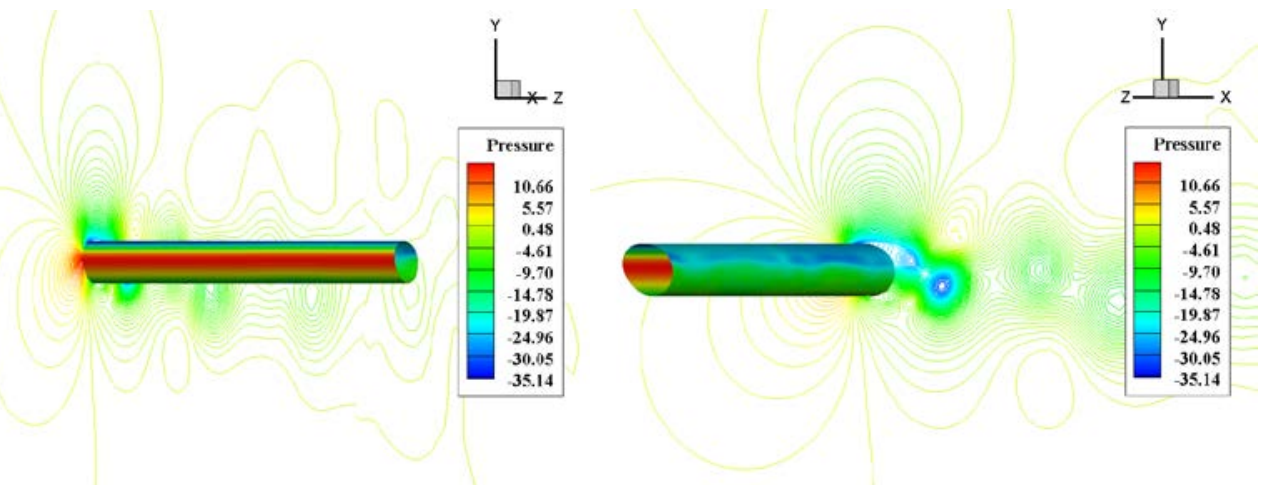

Fig.4 Surface pressure distribution of symmetrical plane and icing optical fibre at $30^{\circ}$ wind angle at wind speed of $5 \mathrm{~m} / \mathrm{s}$

Results of shape coefficients under $5 \mathrm{~m} / \mathrm{s}$ and $15 \mathrm{~m} / \mathrm{s}$ wind speed conditions are shown as Fig.5. From the figures, it can be seen that shape coefficient isn't obvious changed when wind speed increase. Reynolds number of the icing OPGW optical cable lies within sub-critical scope under these two wind speed conditions. Change of shape coefficient within this scope isn't obvious, and it is similar to result of the shape coefficient in sub-critical area of the single column. When attack angle of wind rises up to $90^{\circ}$ from $0^{\circ}$, windward area increases continuously, which causes the shape coefficient increase; when wind attack angle rises up to $180^{\circ}$ from $90^{\circ}$, windward area decreases continuously and icing faces towards downstream, which has certain guiding effect on air flow. Therefore shape coefficient at wind attack angle of $120^{\circ}$ is less than result at $60^{\circ}$, shape coefficient at $150^{\circ}$ is less than result at $30^{\circ}$. Icing causes scope of the adverse pressure gradient which is broadcasted upstream is wider at wind attack angle of $180^{\circ}$, therefore its shape coefficient is greater than that at $0^{\circ}$.

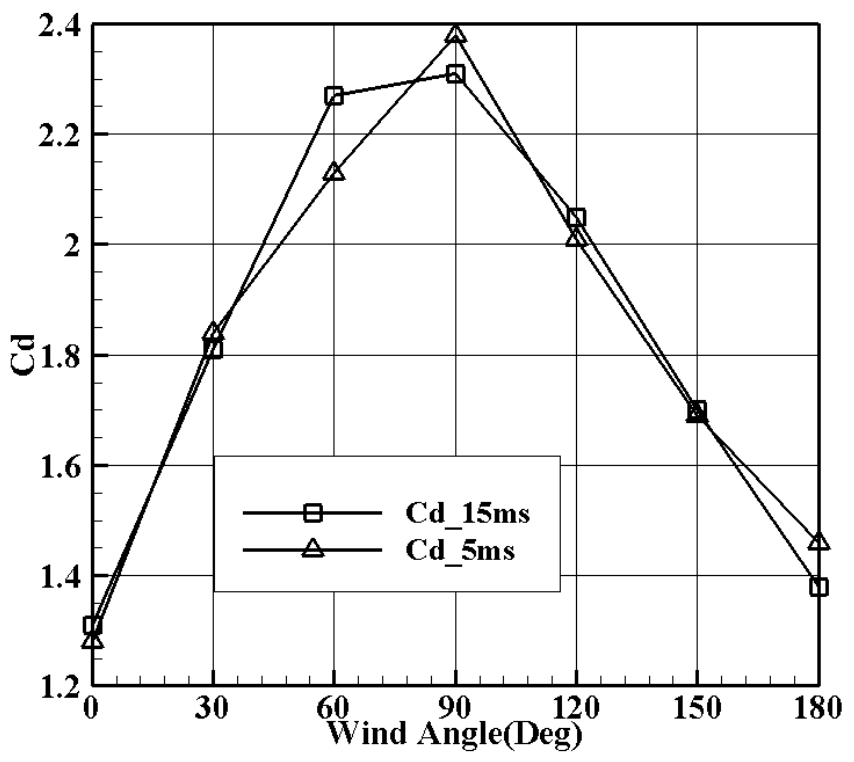

Fig.5 Change of shape coefficient of $5 \mathrm{~mm}$ icing following wind direction angle

\section{Result of 20mm icing}

Result at $60^{\circ}$ wind direction angle under $15 \mathrm{~m} / \mathrm{s}$ wind speed condition is shown as Fig.6. Seen from the figure, there is obvious three dimension effect on surface pressure distribution at leeward side. Shape coefficient result under $20 \mathrm{~mm}$ icing condition is shown as Fig.7. The trend of its shape coefficient is consistent, and maximum shape coefficient also occurs at $90^{\circ}$ wind direction angle. 

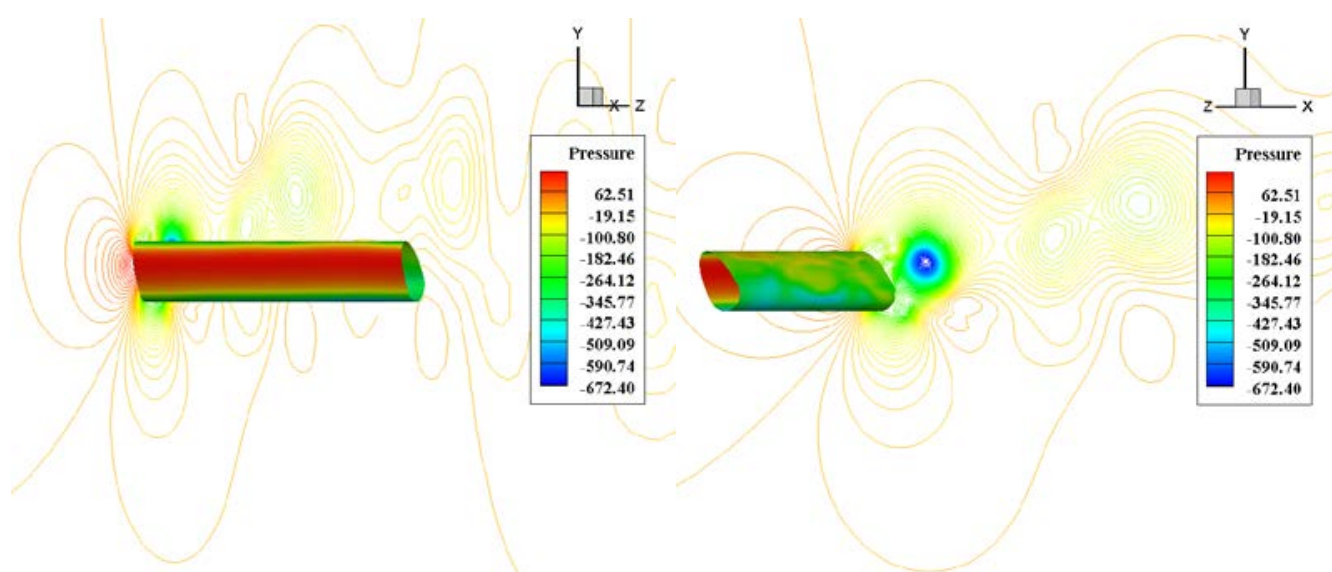

Fig.6 Surface pressure distribution of symmetrical plane and icing optical cable at $60^{\circ}$ wind angle at wind speed of $15 \mathrm{~m} / \mathrm{s}$

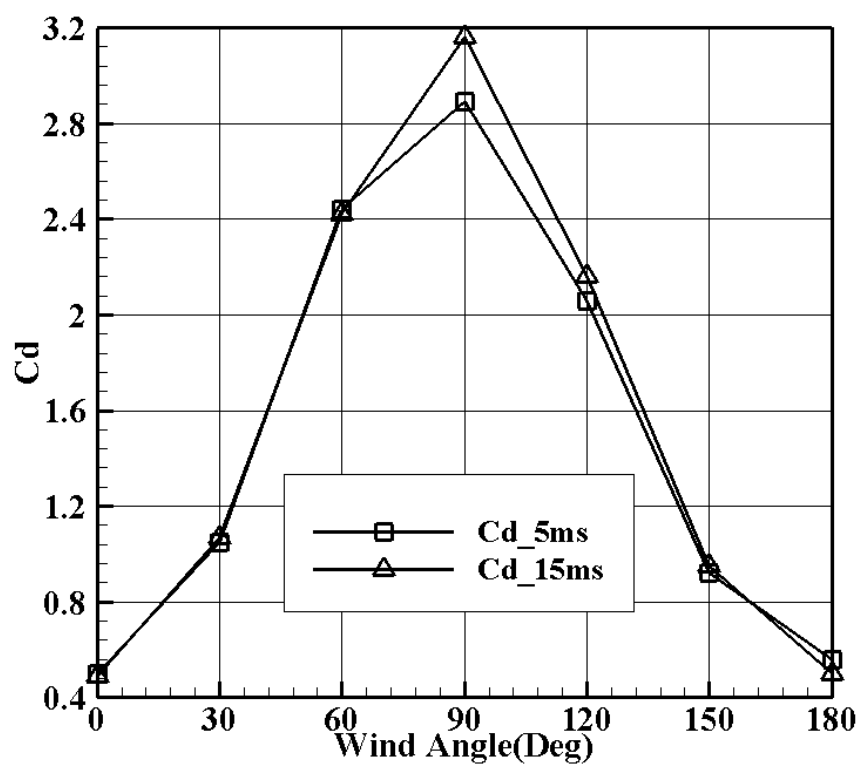

Fig.7 Comparison of shape coefficient under different wind speed conditions

\section{Influence of icing thickness on shape coefficient}

Shape coefficient results under different icing thickness conditions and same wind speed conditions are shown as Fig.8. Seen from the figures, maximum shape coefficient increases following increasing of icing thickness. Because icing thickness increases, icing shape has certain improvement effect on flowing separation when wind direction angle is less than $50^{\circ}$; after wind direction angle is greater than $120^{\circ}$, icing is located at leeward side, increasing of icing thickness strengthens its guiding effect on air flow, and its shape coefficient drops down. 


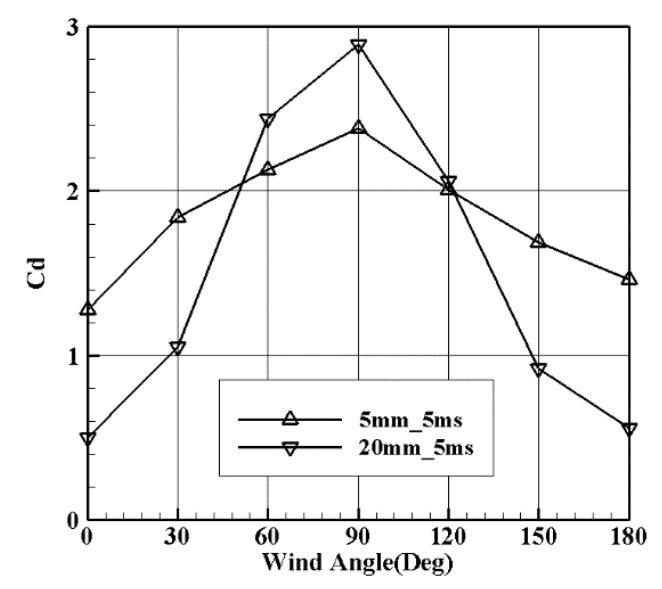

(a) $5 \mathrm{~m} / \mathrm{s}$ wind speed

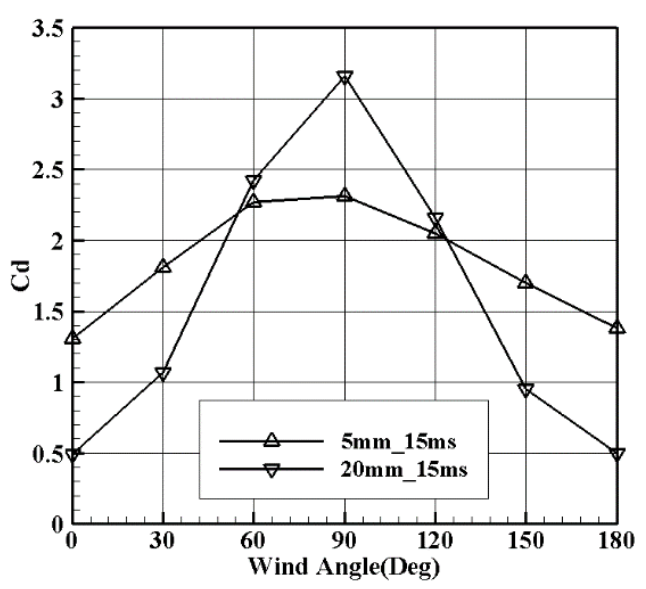

(b) $15 \mathrm{~m} / \mathrm{s}$ wind speed

Fig.8 Shape coefficient under different icing thickness conditions

\section{Summary}

NS equation enclosed by Transition SST turbulence model is applied to simulate flow field of the OPGW optical cable under different wind speeds when icing thicknesses are $5 \mathrm{~mm}$ and $20 \mathrm{~mm}$, and shape coefficient is calculated. The results show that there is obvious three dimensional effect in OPGW flow field in crescent shaped icing; shape coefficients of $5 \mathrm{~mm}$ icing or $20 \mathrm{~mm}$ icing are basically consistent at different wind speed conditions, it means its shape coefficients are not sensitive to Reynolds number; increasing of icing thickness has obvious influence on shape coefficient under same wind speed conditions: when wind angle is less than $50^{\circ}$ or greater than $120^{\circ}$, icing thickness is increased and the shape coefficient drops down; when wind angle lies within wind direction angle section of $50^{\circ} \sim 120^{\circ}$, increasing of icing thickness will cause windward area increase, its shape coefficient is increased obviously following increasing of icing thickness.

\section{Acknowledgement}

Funded by State Grid Corporation of China (No.GC71-13-035)

Funded by National Foundation of China (No.51308519)

\section{References}

[1] SUN Zhenmao, LOU Wenjuan, Nonlinear Finite Element Analysis on Galloping of Ice-Coated Transmission Line[J], Power System Technology, 2010, 34(12): 214-218.

[2] YANG Fengli, YANG Jingbo, FU Dongjie, LI Qinghua, Analysis on the Loads From Galloping Conductors of Transmission Lines[J], Proceedings of the CSEE, 2011, 31(16): 102-107

[3] YAO Chen-guo, MAO Feng, XU Dao-lin, Mechanical Properties of Transmission Tower-line System in Non-uniformly Iced Condition, High Voltage Engineering, 2011,37(12):3084-3092

[4] HAN Junke,YANG Jingbo,LI Qinghua,et al.,Analysis on Unbalanced Tension Caused by Ice-Coating on Conductors of UHV/EHV AC Multi-Circuit Transmission Lines on the Same Tower, Power System Technology, 2011,35(12):33-37

[5] Ji Jin-chuan,Gao Yi-bin,Dong Yong-jun,et al., Reason Analysis of OPGW Breakage Caused by Ice Cover, NORTH CHINA ELECTRIC POWER,2008, 7,15-17

[6] XIAO Zheng-zhi,YAN Zhi-tao,LI Zheng-liang, et al., Wind Tunnel and Aerodynamic Characteristics Tests for Ice-Covering of Transmission Line Adopting 8-Bundled Conductor, Power System Technology,2009,33(5):90-94 
[7] LI Xinmin, ZHU Kuanjun, LIU Bin, Numerical and Experimental Simulation of Aerodynamic Characteristics of Typical Iced Co, High Voltage Engineering, 2014,40(2):427-433

[8] Jianing Peng, Dongliang Zhang, Gaoyu Zhao, Meihua Bian, Research on Regulary of the Aerodynamic Charactersstics of Iced Condutor, Chinese Journal of Solid Mechanics,2014, 35(S.Issue): 202-207

[9] WANG Xin, LOU Wen-juan,SHEN Guo-hui,A wind tunnel study on aerodynamic characteristics of iced conductor, ACTA AERODYNAMICA SINICA,2011,29(5):573-579

[10]ZHANG Hong-yan,YAN Bo,LIU Xiao-hui, Wind-tunnel tests for aerodynamic characteristics and galloping behaviors of iced conductors, Journal of Vibration and Shock, 2013,32(10):95-99

[11]LV Yi, LOU Wen-juan, SUN Zhen-mao, Numerical simulation of aerodynamic characteristics of three bundled iced transmission lines, Journal of Zhejiang University(Engineering Science), 2010,44(1):174-179

[12]CAI Meng-qi, YAN Bo, LV Xin, Numerical Investigation on Aerodynamic Coefficients of Iced Bundle Conductor, Journal of Vibration and Shock, 2013,32(5):132-137

[13]Barth, T.J., and Jesperson, D.C,“The Design and Application of Upwind Schemes on Unstructured Meshes”,AIAA Paper 89-0366, 1989 